\title{
Formation of a Basic Target Plan as a Foundation of Goal-Setting in Strategic Planning for Regional Socio-Economic Development
}

\author{
Vladimir Tsybatov \\ Leonid Mikhaylovsky
}

Samara State University of economics; Email: tva82@yandex.ru

Doi:10.5901/mjss.2015.v6n6s3p478

\begin{abstract}
The beginning of a new stage in the development of regional strategic planning in the Russian Federation has actualised the issues connected with scientific and methodological support for elaboration of strategies for long-term regional socioeconomic development, in particular those related to regional goal-setting. This study attempts at substantiating a new approach to formation of the basic target plan for socio-economic development of a region. This plan is intended to act as an "incompressible core" of goal-setting, common to all regional strategies. The proposed plan is based on the concept of wellbeing as interpreted by the statistical commission of the Organisation for Economic Cooperation and Development (OECD) and Stiglitz-Sen-Fitoussi's commission. The plan contains a hierarchically ordered set of generally valid goals and target indicators describing the desirable level of well-being and potential for its reproduction. The proposed basic target plan can be used by the subjects of the Russian Federation in the process of elaboration of their strategies for socio-economic development.
\end{abstract}

Keywords: region, regional strategic planning, well-being, goal-setting, basic target plan.

\section{Introduction}

At the present time, strategic planning is viewed as one of the most widespread and effective instruments of regional socio-economic and spatial development (Dimitrou and Thomson, 2008; Vasilevska and Vasic, 2009). This tool is also widely used in the Russian Federation, which is reflected in the practice of elaboration of various regional strategic planning documents. The most important document of strategic planning at the regional level (level of the subject of the Russian Federation) is the regional strategy for socio-economic development. To date, 79 subjects of the Russian Federation out of 85 have these strategies (Kurkin, 2014).

Currently, in the Russian Federation there is a reorganisation of the system of regional strategic planning initiated by adoption in 2014 of the Federal Law N 172-FZ "On strategic planning in the Russian Federation".According to this law, elaboration of strategies for long-term regional socio-economic development stops being only the right of the subjects of the Russian Federation and becomes their duty. The law also contains a significant amount of requirements to organisation of regional strategies elaboration and to the need for their coherence with federal strategic planning documents. In this connection it can be considered as a step on the way to unification of regional strategic planning practices, which until recently differed considerably (Federal Law "On strategic planning in the Russian Federation", 2014).

In spite of the fact that the new law on strategic planning is not a framework law (one) as it contains the detailed description of requirements for regional strategies elaboration, a number of methodological issues remain unresolved. Among those are the issues related to organisation of the goal-setting process which is traditionally considered as one of the weak spots of regional strategy elaboration. The current practices of regional goal-setting differ in approaches with regard to goals identification and are characterised by generally insufficient level of scientific and methodological support.

Meanwhile, in our opinion, an obligatory character of regional strategic planning coupled with the leading role of the state in its regulation and control implies that there should be a "common denominator" in regional goal-setting reflecting the measure of the "due" in regional socio-economic policyfrom the perspective of modern scientific views and the current practice of regional governance. The solution to this problem, which determined the goal of the present study, in our view lies in formation of a basic target plan for socio-economic development of the subjects of the Russian 
Federation. This plan should contain a hierarchically ordered set of generally valid goals and target indicators corresponding to the main directions of functioning and development of a region. It should be noted that besides concentrated expression of interests of the subject of the Russian Federation, a basic plan has to allow expansions connected with main long-term federal center priorities concerning the subjects of the Russian Federation. For today these priorities are reflected in such documents as "Criteria for the assessment of the effectiveness of the executive bodies of subjects of the Russian Federation" and "May decrees" of the President V. Putin (Presidential decrees of the Russian Federation of 7.05.2012 №№ 596-606).

The proposed basic target plan is certainly not designed to cover all the variety of regional problems. This plan will not substitute regional goal-setting process in general, acting only as its "incompressible core" which is common to all regional strategies.

\subsection{Literature Review}

There are several groups of studies relevant to the subject of this paper's issues in accordance with the stated goal of the research.

Firstly, studies which attempt at formulation of general goals and criteria of development of socio-economic systems. Here the most significant work is the report by the Commission on the measurement of economic performance and social progress which gained wide public recognition (Stiglitz-Sen-Fitoussi commission) (Stiglitz et al., 2009). The goal of this commission was the search for others than GDP criteria for measuring of social and economic progress. This report summarizes the results of several decades of work in the field of measurement of GDP, living standards, quality of life and sustainable development. In this report population well-being is justified as the most important complex characteristic of socio-economic development and present and perspective indicators for its measurement are considered. This circumstance is valuable from the methodological point of view and therefore should be accounted for in the process of elaboration of the basic target plan for socio-economic development. A lot of attention also deserves significant methodical work on improvement of well-being assessment and measurement criteria, which is carried out by the statistical commission of the Organisation for Economic Cooperation and Development. Results of this work are regularly published in the corresponding OECD reports (OECD, 2011, 2013).

Secondly, the studies dealing with general methodological issues of regional goal-setting in the process of carrying out of regional socio-economic policy. The study (Shekhovtseva, 2008) researched features of the region as a subject of goal-setting stemming from its properties as a territorial and governmental entity.lt also proposes a new typology of regional goals according to which there can be defined three groups of regional development goals: macroeconomic, mesoeconomic and microeconomic. The study (Makhotayeva, 2006) reveals logic and sequence of the stages of defining regional development goals as well as the issues of methodological support for the goal-setting process.

Thirdly, "applied" studies exploring the problems of goal-setting in relation to elaboration of strategies for socioeconomic development of the subjects of the Russian Federation. Among them there are studies attempting at substantiation of target regional development plans based on objectives tree type decomposition with author's interpretation of the concept of quality of life (Rudenko, 2013). There can be also found various criteria of selection of regional development goals: based on main regional subsystems, based on main target segments of a region (Chmyshenko and Chmyshenko, 2014).

Fourthly, studies dealing with the issues of use of social and economic indicators in the practice of management, both in general (Delorme and Chatelain, 2011) and in relation to issues of regional and city planning (Wong, 2006). Importance of studies of the last group is determined by the indicators' role as both independent elements of goalsetting and a way of operationalisation of higher order goals.

\section{Methodological Research Framework}

In the authors' view, the main subject of regional governance and, accordingly, the main adressee of the proposed target plan are recognised to be regional authorities. They are also collectively referred to as direct subject of regional governance as opposed to the final subject of regional governance, represented by regional population as a whole (Seliverstov, 2010).

As a theoretical basis for determination of the main strategic goal, we used the concept of economic well-being as interpreted by the Statistical commission of OECD (OECD, 2013). According to this interpretation, population well-being may be decomposed into the following components: material living conditions (or economic well-being), quality of life (or 
non-monetary characteristics of well-being), and the economic system's sustainability as a necessary condition for its reproduction. It should be noted that this approach in its turn draws on one proposed by Stiglitz-Sen-Fitoussy commision (Stiglitz et al., 2009).

To hierarchically organise the system of regional development goals and indicators, we used objectives (or goals) tree method. This method is implemented in several steps.At first the main strategic (general) goal is defined which is then to be decomposed into the system of the first level goals. Similarly, the second level goals are formed by the detailed indicators of the first level goals.In their turn, the second level goals are decomposed into the corresponding subordinate third level goals, etc.Taken together, the lower level goals and the main strategic goal form economic agents' objectives (goals) tree. Decomposition process is deemed completed upon reaching the level of "final" objectives, or economic agents' direct management tools. It should be taken into account that some of the objectives tree method's assumptions are too restrictive to be observed. In practice, the requirement of sub-goals' independence is hardly feasible due to the existence of numerous interrelations within the regional system. On the other hand, the existence of socioeconomic systems' emergent properties means that achievement of a certain goal can not be fully reduced to achievement of its sub-goals. Nevertheless, this method is rather convenient and widespread in practice

To obtain an evaluation of the degree to which the stated goals are achieved, we use target indicators which define these goals' characteristics quantitatively. In choosing the set of indicators, we proceed from the requirement of their statistical measurability: we will use only those indicators information on which can be obtained from official sources on a regular basis. Given the regional statistics' insufficient development, it should be noted that this requirement constitutes a serious restriction.

\section{Results of Research}

\subsection{Construction of a basic objectives (goals) tree of socio-economic development of the subject of the Russian Federation.}

The construction of the basic objectives (goals) tree for socio-economic development of the subjects of the Russian Federation should be started from formulation of the main strategic goal. In order to do so, we will build on the results contained in the Stiglitz-Sen-Fitoussi commission report (Stiglitz et al., 2009) and in the report of Statistical commission of OECD (OECD, 2013) where the main strategic goal of socio-economic systems' functioning is defined as ensuring of sustainable population well-being.

In decomposing the main strategic goal into its basic components, we proceed from the assumption that any strategy aims at best allocation of the resources created during the reproduction process. There are two traditional directions of using available resources: current consumption and capital accumulation. This holds true for both individuals and regions (and states). Current consumption ensures living conditions maintenance, and capital accumulation ensures current consumption's reproduction. This means that capital accumulation should not be regarded as an end in itself. Capital is important only in so far as it acts as an instrument for capacity building for further development. If today we have invested part of the income in the capital, tomorrow we have the right to expect to receive the desirable economic goods. Therefore the main strategic goal is to be decomposed into the two goals. The first goal should characterise desirable parameters of the economic goods consumed, the second - capital to labour ratio. From the perspective of individuals in their capacity of final consumers of the economic goods produced, it is logical to designate the following first level goals:

1. Achievement of a "decent" level of population well-being.

2. Capacity building for regional sustainable development.

The concept of "decent" level of well-being is a flexible one as its exact meaning depends on the type of the region we are dealing with. For some subjects of the Russian Federation, "decent" level means average European level, for the less developed subjects, it denotes average Russian level of population well-being. Realisation of the stated goals involves achievement of the desirable level of well-being on the basis of sustainable economic growth and, speaking more broadly, on the basis of building of a competitive model of the regional economy capable of creating sustainable economic growth and material resources for ensuring of the desirable level of well-being.

Our approach to decomposing the first level goals draws closely on one proposed by the Stiglitz-Sen-Fitoussi' commission. According to this approach, the following components of well-being can be identified.

1. Material well-being (living standards or living conditions), characterising the degree to which people have command over economic resources and shaping their consumption opportunities and consumption patterns.

2. Quality of life, or non-monetary well-being attributes, determining opportunities for human potential realisation 
and regarded (viewed) as values in different cultures and contexts. There can be determined several features of quality of life (Stiglitz et al., 2009):

- state of health and health care system development;

- education system development;

- social connections;

- personal activities;

- political voice and quality of public governance;

- environmental conditions;

- personal security;

- economic security.

3. Socio-economic system's sustainability which shows whether the achieved level of well-being can be increased or at least maintained over time. Socio-economic system's sustainability characterises impact of human activity on different types of capital - natural, economic, human, social - which are indispensable for ensuring of well-being (OECD, 2013).

Components of the first two groups reflect quality of the consumed economic goods created by the economy. Therefore, they can be used for decomposition of the goal "Achievement of a "decent" level of population well-being". The third group of components characterises the quality of the accumulated capital capable of generating sustainable economic growth and creating material basis for ensuring of the desirable level of well-being. This group of components is advisable to use for decomposition of the goal "Capacity building for sustainable development". In performing goals decomposition, we will not consider those goals which require using indicators unobtainable from official sources.

The results of the first level goals decomposition are given in Tables 2.1-2.13. Table 2.1 lists the second level goals used to detail the corresponding first level goals.

Table 2.1. First level goals specification

\begin{tabular}{|l|}
\hline Goal 1. Achievement of decent level of population well-being \\
\hline Goal 1.1. Achievement of decent population standard of living \\
\hline Goal 1.2. Life expectancy increase and population saving \\
\hline Goal 1.3. Advancing development of social infrastructure and ensuring of ecological safety \\
\hline Goal 2. Capacity building for sustainable development \\
\hline Goal 2.1. Development of economic potential \\
\hline Goal 2.2. Ensuring of financial independence \\
\hline Goal 2.3. Ensuring of output growth and efficient structure of the regional economy \\
\hline
\end{tabular}

In their turn, the second level goals are decomposed into the third level goals (Tables 2.2-2.7). The objectives (goals) tree thus obtained is illustrated in Figure 2.1.

Figure 2.1. Basic objectives (goals) tree of the subject of the Russian Federation

Table 2.2. Decomposition of the goal 1.1 into sub-goals

\begin{tabular}{|l|}
\hline Goal 1.1. Achievement of decent population standard of living \\
\hline 1.1.1. Population real income increase to decent level \\
\hline 1.1.2. Poverty liquidation \\
\hline 1.1.3. Effective social security system creation \\
\hline 1.1.4. Population capitalisation increase \\
\hline 1.1.5. Increase of level of human potential \\
\hline
\end{tabular}

Table 2.3. Decomposition of the goal 1.2 into sub-goals

Goal 1.2. Life expectancy increase and population saving

1.2.1. Demographic situation improvement

1.2.2. Infant mortality reduction

1.2.3. Life expectancy increase 
Table 2.4. Decomposition of the goal 1.3 into sub-goals

\begin{tabular}{|l|}
\hline Goal 1.3. Advancing development of social infrastructure and ensuring of ecological safety \\
\hline 1.3.1. Social infrastructure improvement \\
\hline 1.3.2. Priority to the development of education, health care and culture \\
\hline 1.3.3. Ecological safety ensuring system development and environment protection \\
\hline
\end{tabular}

Table 2.5. Decomposition of the goal 2.1 into sub-goals

\begin{tabular}{|l|}
\hline Goal 2.1. Development of economic potential \\
\hline 2.1.1. Labour potential development and ensuring of population employment \\
\hline 2.1.2. Effective migration policy implementation \\
\hline 2.1.3. Investment activity increase \\
\hline 2.1.4. Fixed capital modernisation \\
\hline
\end{tabular}

Table 2.6. Decomposition of the goal 2.2 into sub-goals

Goal 2.2. Ensuring of financial independence

2.2.1. Optimisation of tax incomes of the consolidated budget

2.2.2. Optimisation of expenses of the consolidated budget

2.2.3. Government debt reduction

Table 2.7. Decomposition of the goal 2.7 into sub-goals

\begin{tabular}{|l|}
\hline Goal 2.3. Ensuring of output growth and efficient structure of the regional economy \\
\hline 2.3.1. Stimulation of growth of goods and services output \\
\hline 2.3.2. Regional economy efficiency increase \\
\hline 2.3.3. Regional economy structure optimisation \\
\hline 2.3.4. Foreign trade relations development \\
\hline
\end{tabular}

\subsection{Identification of main socio-economic indicators to quantify the stated system of regional development goals.}

To form a quantitative assessment of the degree to which the stated goals are achieved, it is important that each knot of the objectives tree have one or several corresponding target indicators. Within the framework of the model used, target indicators are defined as integral quantitative characteristics of socio-economic development, related to policy impact measurement.

As it was mentioned above, in determining the target indicators, we proceed from the requirement of their statistical measurability: only those indicators were used that can be obtained on a regular basis from official sources. Table 2.8 lists target indicators which should be used for quantification of the goal 1.1 "Achievement of decent level of population standard of living".

Table 2.8. Target indicators for the goal 1.1

\begin{tabular}{|l|l|}
\hline Goals & Target indicators \\
\hline Goal 1.1. Achievement of decent level of population standard of living & \\
\hline 1.1.1. Population income increase to the decent level & Growth of real per capita disposable population income, \% to the base year \\
\hline 1.1.2. Poverty liquidation & Share of population with the income below the subsistence rate, \% \\
\cline { 2 - 2 } & Decile income differentiation coefficient \\
\hline 1.1.3. Effective social security system & Replacement coefficient for the pension income, \% \\
\hline 1.1.4.Population capitalisation increase & Total area of premises on average per one inhabitant, sq.m \\
\hline 1.1.5. Increase of level of human potential & Human Development Index (HDI) \\
\hline
\end{tabular}

Table 2.9 lists target indicators used for quantification of the goal 1.2 "Life expectancy increase and population saving". The most important among them are those characterising regional demographic trends (issues). They have recently gained particular importance due to the threats posed by depopulation. 
Table 2.9. Target indicators for the goal 1.2

\begin{tabular}{|l|l|}
\hline Goals & Target indicators \\
\hline Goal 1.2. Life expectancy increase and population saving & \\
\hline \multirow{2}{*}{ 1.2.1 Demographic situation improvement } & Number of resident population (average annual) - total number, thousands of people \\
\cline { 2 - 2 } & Total fertility rate per woman \\
\hline 1.2.2. Infant mortality reduction & Infant mortality, per mille \\
\hline 1.2.3. Life expectancy increase & Life expectancy at birth, years \\
\hline
\end{tabular}

Table 2.10 lists target indicators used for quantification of the goal 1.3 "Advancing development of social infrastructure and ensuring of ecological safety". The aspects of quality of life related to social infrastructure are difficult to quantify. Therefore, the indicators used to quantify them are mainly those connected with demographic trends and distribution of budgetary funds.

Table 2.10. Target indicators for the goal 1.3

\begin{tabular}{|l|l|}
\hline Goals & Target indicators \\
\hline $\begin{array}{l}\text { Goal 1.3. Advancing development of social infrastructure and ensuring of } \\
\text { ecological safety }\end{array}$ & \\
\hline \multirow{2}{*}{$\begin{array}{l}\text { 1.3.1. Social infrastructure improvement } \\
\text { 1.3.2. Priority to the development of education, health care and culture }\end{array}$} & $\begin{array}{l}\text { Preschool educational institutions availability, places per } 1000 \text { children of } \\
\text { preschool age }\end{array}$ \\
\cline { 2 - 2 } $\begin{array}{l}\text { 1.3.3. System of ecological safety ensuring development and environment } \\
\text { protection }\end{array}$ & Expenses on health care, \% to GRP of the region. \\
\cline { 2 - 2 } & Expenses on education, \% to GRP of the region \\
\hline
\end{tabular}

Table 2.11 lists target indicators used for quantification of the goal 2.1 "Development of economic potential". The selected target indicators characterise the state of the main production factors - labour and capital. The labour force is described by indicators of employment and unemployment. The condition of fixed capital is described by the indicators of capital injection and capital retirement.

Table 2.11. Target indicators for the goal 2.1

\begin{tabular}{|l|l|}
\hline Goals & Target indicators \\
\hline Goal 2.1. Development of economic potential & \\
\hline \multirow{4}{*}{$\begin{array}{l}\text { 2.1.1. Labour potential development and } \\
\text { ensuring of population employment }\end{array}$} & Share of employees in the economy (average annual) in the total number of labor resourses, \% \\
\cline { 2 - 2 } & $\begin{array}{l}\text { Share of employees average number of small and medium-sized enterprises in employees average } \\
\text { number of all enterprises and organisations, \% }\end{array}$ \\
\cline { 2 - 2 } & Share of employees in public administration, \% to the number of employed people \\
\cline { 2 - 2 } & Unemployment rate (according to methodology of the International Labour Organisation), \% \\
\hline 2.1.2. Effective migration policy implementation & Share of labour migrants in the number of the employed people in the region, \% \\
\hline 2.1.3. Investment activity increase & Norm of fixed capital accumulation, \% to GRP \\
\hline 2.1.4. Fixed capital modernisation & Wear degree of fixed capital by the end of the year, \% \\
\hline
\end{tabular}

Table 2.12 lists target indicators used for quantification of the goal 2.2 "Ensuring of financial independence". These indicators characterise the formation and use of financial resources available to regional authorities. The optimising character of these indicators implies that their target values should be set as intervals.

Table 2.12. Target indicators for the goal 2.2

\begin{tabular}{|l|l|}
\hline Goals & Target indicators \\
\hline Goal 2.2. Ensuring of financial independence & \\
\hline \multirow{2}{*}{ 2.2.1. Optimisation of consolidated budget tax incomes } & Share of own incomes, including taxes, in the regional budget structure, \%; \\
\cline { 2 - 2 } 2.2.2. Optimisation of consolidated budget expenses & $\begin{array}{l}\text { Regional budget deficiency, \% to the regional budget expenses } \\
\text { expenses; }\end{array}$ \\
\hline 2.2.3. Government debt reduction & Government debt of the region, \% to GRP \\
\hline
\end{tabular}


Table 2.13 lists target indicators used for quantification of the goal 2.3 "Ensuring of output growth and regional economy efficiency". These target indicators characterise the desired level of the economic growth, the costs of the reproduction process, basic proportions of the economy and the region's economic relations with foreign countries.

Table 2.13. Target indicators for the goal 2.3

\begin{tabular}{|l|l|}
\hline Goals & Target indicators \\
\hline $\begin{array}{l}\text { Goal 2.3. Ensuring of output growth and efficient structure of } \\
\text { the regional economy }\end{array}$ & \\
\hline 2.3.1. Stimulation of growth of goods and services output & Average annual index of physical volume of GRP, \% \\
\hline \multirow{2}{*}{ 2.3.2. Regional economy efficiency increase } & Share of intermediate consumption in goods and services output, $\%$ \\
\cline { 2 - 2 } & Power consumption of GRP, tons of equivalent fuel per one million rubles \\
\hline \multirow{2}{*}{ 2.3.3. Regional economy structure optimisation } & Share of high-tech and knowledge-intensive economy industries in GRP, $\%$ \\
\cline { 2 - 2 } & Share of small and medium-sized enterprises in goods and services output, $\%$ \\
\hline \multirow{2}{*}{ 2.3.4. Foreign trade relations development } & Export growth to the base year, $\%$ \\
\cline { 2 - 2 } & Import growth to the base year, $\%$ \\
\hline
\end{tabular}

\subsection{Structure of the regional strategic (target) plan.}

The structure of the proposed basic target plan is given in Table 2.14. The first column shows the serial numbers of the target indicators. The second column shows the names and measurement units of the target indicators grouped by thematic areas. The third column shows the values of the target indicators in the base year. If the indicator's measurement unit is defined "in \% to the base year", its value in the base year is taken for $100 \%$. The last column gives the target year and values of the target indicators set for that year. These target values are used to describe the desirable future state of a region, at achievement of which the strategy is aimed. Issues of indicators' target values balance and attainability are different ones and therefore should be treated separately (Tsybatov, 2015).

Table 2.14. Basic target plan (example)

\begin{tabular}{|c|c|c|c|}
\hline \multirow{3}{*}{ № } & \multirow{3}{*}{ Indicators of socio-economic development of the subject of the Russian Federation } & Base year & Target year \\
\hline & & 2012 & 2030 \\
\hline & & \multicolumn{2}{|c|}{ Indicator value } \\
\hline & 1. Population well-being & & \\
\hline 1 & Real per capita growth of disposable population income, $\%$ to the base year & 100,0 & 200,0 \\
\hline 2 & Replacement coefficient for pension incomes, \% & 42,5 & 40,0 \\
\hline 3 & Share of population with the income below the subsistence rate, $\%$ & 12,4 & 7,0 \\
\hline 4 & Decile differentiation income coefficient & 19,6 & 13,0 \\
\hline \multirow[t]{2}{*}{5} & Total area of premises on average per one inhabitant, sq.m & 22,8 & 35,0 \\
\hline & 2. Demography & & \\
\hline 6 & The number of resident population (average annual) - total number, thousands of people & 3213,7 & 3200 \\
\hline 7 & Total fertility rate per woman & 1,5 & 1,7 \\
\hline 8 & Infant mortality rate, per mille & 7,0 & 4,0 \\
\hline \multirow[t]{2}{*}{9} & Expected life expectancy at birth, years & 69,7 & 75,0 \\
\hline & 3. Social policy & & \\
\hline 10 & Preschool educational institutions availability, places per 1000 children of preschool age & 670,0 & 750,0 \\
\hline 11 & Crime rate (quantity of registered crimes), per 100 thousand people & 1882,6 & 1250,0 \\
\hline 12 & Expenses on health care, \% to GRP of the region. & 4,5 & 6,0 \\
\hline \multirow[t]{2}{*}{13} & Expenses on education, \% to GRP of the region & 3,9 & 4,5 \\
\hline & 4. Labour recourses and fixed capital & & \\
\hline 14 & Share of the employed in economy (average annual) in the total number of labor resourses & 72,3 & 74,0 \\
\hline 15 & $\begin{array}{l}\text { Share of employees average number of small and medium-sized enterprises in employees average number of all } \\
\text { enterprises and organisations, \% }\end{array}$ & 26,3 & 33,0 \\
\hline 16 & Share of the employed in state administration, $\%$ to the number of employed people & 6,6 & 5,0 \\
\hline 17 & Unemployment rate (according to methodology of the ILO), \% & 3,8 & 3,0 \\
\hline 18 & Share of labour migrants in the number of the employed in the region, \%; & 2,3 & 3,0 \\
\hline 19 & Norm of fixed capital accumulation, \% to GRP & 21,5 & 21,0 \\
\hline \multirow[t]{2}{*}{20} & Wear rate of fixed capital by the end of the year, $\%$ & 52,0 & 30,0 \\
\hline & 5. Financial resources & & \\
\hline 21 & Share of own incomes, including taxes, in regional budget structure, $\%$ & 89,2 & 90,0 \\
\hline 22 & Regional budget deficiency, \% to the regional budget expenses & 7,6 & 1,0 \\
\hline 23 & Share of management and law-enforcement activity expenses, $\%$ to the regional budget expenses; & 10,5 & 9,0 \\
\hline
\end{tabular}




\begin{tabular}{|l|l|c|c|}
\cline { 2 - 3 } 24 & Government debt of the region, \% to GRP & 11,2 & 3,0 \\
\hline & 6. Economic growth and efficiency of economy & & \\
\hline 25 & Average annual index of physical volume of GRP, \% & 105,5 & 103,0 \\
\hline 26 & Share of intermediate consumption in goods and services output, \% & 54,0 & $\mathbf{5 0 , 0}$ \\
\hline 27 & Share of high-tech and knowledge-intensive industries of economy in GRP, \%; & 11,1 & 15,0 \\
\hline 28 & Share of small and medium-sized enterprises in goods and services output, \% & 31,7 & 35,0 \\
\hline 29 & Export growth to the base year, \% & 100,0 & 130,0 \\
\hline 30 & Import growth to the base year, \% & 100,0 & 100,0 \\
\hline
\end{tabular}

\section{Discussion}

The developed basic objectives (goals) tree (Figure 2.1) is proposed to be used as goal-setting "core" within the framework of strategic planning for regional socio-economic development. Thus constructed target plan (Table 2.14) is expedient to use as a basis for expanded target plan of the subject of the Russian Federation. This expanded target plan will also include long-term priorities of the Russian Federation in relation to the subjects of the Russian Federation and the latters' local goals (for instance, to build a bridge over the river). The developed system of target indicators (Tables 2.8-2.13) can serve as a universal instrument for regional condition measurement applicable for organisation of monitoring of efficiency of regional strategy implementation in line with the stated goals. The structure of the basic target plan was formed as a projection of modern ideas about the nature of the concept of well-being on the current system of regional statistics taking also into account the characteristics of the federal structure of the Russian Federation and current trends in the federal regional policy. Needless to say, changes in each component will potentially lead to correction of the plan. In particular it concerns the system of regional statistics which today is the major limiting factor owing to whose influence it is difficult to give an adequate assessment to non-monetary components of well-being, particularly to social infrastructure. Respectively, debottlenecking in this sphere will serve as an important improvement source for the proposed target plan.

Issues of indicators' target values balance and attainability are different ones and therefore should be treated separately. In setting values of target indicators, a researcher proceeds from a certain desirable state of a region which should be balanced in terms of harmonious view of socio-economic development. However, the stated goals may be unbalanced in terms of incomparable complexity of their achievement.

So, there should be a compromise between the desirable future state of a region and the region's ability to achieve this state, defined by the available resources in the conditions of their optimal allocation. This problem is to be solved by special means (Tsybatov, 2015) at the stage of indicators' target values attainability assessment. Results of this stage will allow to carry out implementability assessment of the strategy formed, to analyse alternatives for regional development and choose the best among them. Proportions, in which indicators, obtained in the course of solving attainability assessment problem, approach set target values, can be used as information for correcting the values of the basic target plan.

\section{References}

Federal law of 28.06.2014 № 172 "On strategic planning in the Russian Federation". Electronic resource. Access mode: http://base .garant.ru/70684666/

Presidential decrees of the Russian Federation of 7.05.2012 №№ 596-606 ("May decrees"). http://base .garant.ru/70170944/

Kurkin K. (2014). Strategic will of Regional Development Ministry. "Expert" magazine. http://expert.ru/northwest/2014/38/strategicheskoezaveschanie-minregionrazvitiyal

Makhotayeva, M.Y. (2006) Theory and methodology of goal-setting in management of regions development. Dissertation of Doctor of Economic Sciences Pskov, 2006.

Rudenko, D.Y. (2013). Hierarchical structure of the global goal of socio-economic regional development. Modern issues of science and education, № 5. http://www.science-education.ru/pdf/2013/5/295.pdf

Seliverrstov, V.E. (2010) Categories evolution and principles of regional strategic planning. Problematic analysis and state management projecting, №. 3, 59-79. Electronic resource. Access mode: http://cyberleninka.ru/article/n/evolyutsiya-kategoriy-i-printsipovregionalnogo-strategicheskogo-planirovaniya

Tsybatov V.A. (2015). Strategy system of regional development. Vestnik. Samara State University of Economics - № 4.

Chmyshenko E.G., Chmyshenko E.V. (2014) Defining objects of regional strategic planning. Vestnik of Omsk State University. http://vestnik.osu.ru/2014_1/13.pdf

Shekhovtseva, L.S. (2008). Formation and modeling of regional strategic goal-setting as a development subject. Zncc ... Dissertation of Doctor of Economic Sciences, Kaliningrad, 2008.

Delorme, P. and Chatelain, O. (2011) Policy steering: The Role and Use of Performance Measurement Indicators, Aid Delivery Methods. 
http://www.dochas.ie/Shared/Files/4/Guide_on_Performance_Measurement.pdf Dimitrou H.T., and R. Thompson. Strategic Planning for Regional Development in UK. Routledge, 2008.

OECD Framework for Statistics on the Distribution of Household Income, Consumtion and Wealth (2013) http://www .oecd.org/statistics/ 302013041e.pdf

Stiglitz, J.E., Sen, A. and J. Fitoussi. 2009. "Report by the Commission on the Measurement of Economic Performance and Social Progress," CMEPSP available at: http://www.stiglitz-sen-fitoussi.fr/documents/rapport_anglais.pdf

Vasilevska L., and M. Vasic. (2009) Strategic Planning as a Regional Development Policy Mechanism - European Context. SPATIUM International Review, No. 21, 19-26. http://www.doiserbia.nb.rs/img/doi/1450-569X/2009/1450-569X0921019V.pdf

Wong, C. (2006) Quantitative indicators for Urban and Regional Planning: Interplay of Policy and Methods. Routledge, 2006. 